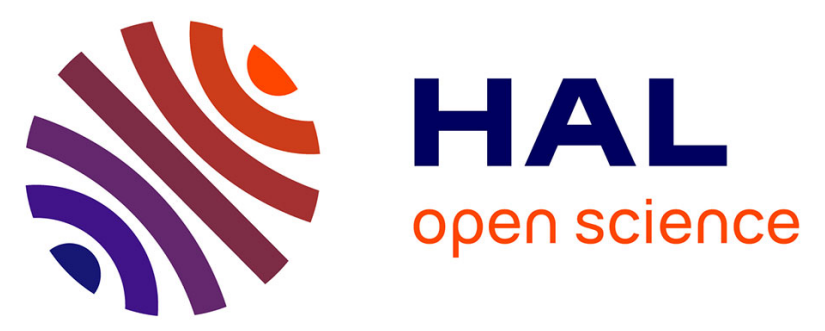

\title{
Combination of thermal and cavitation effects to generate deep lesions with an endocavitary applicator using a plane transducer: ex vivo studies.
}

David Melodelima, Jean Yves Chapelon, Yves Theillère, Dominique Cathignol

\section{- To cite this version:}

David Melodelima, Jean Yves Chapelon, Yves Theillère, Dominique Cathignol. Combination of thermal and cavitation effects to generate deep lesions with an endocavitary applicator using a plane transducer: ex vivo studies.: Combination of thermal and cavitation effects. Ultrasound in Medicine \& Biology, 2004, 30 (1), pp.103-11. 10.1016/j.ultrasmedbio.2003.09.005 . inserm-00189856

\section{HAL Id: inserm-00189856 https://www.hal.inserm.fr/inserm-00189856}

Submitted on 22 Nov 2007

HAL is a multi-disciplinary open access archive for the deposit and dissemination of scientific research documents, whether they are published or not. The documents may come from teaching and research institutions in France or abroad, or from public or private research centers.
L'archive ouverte pluridisciplinaire HAL, est destinée au dépôt et à la diffusion de documents scientifiques de niveau recherche, publiés ou non, émanant des établissements d'enseignement et de recherche français ou étrangers, des laboratoires publics ou privés. 
Combination of thermal and cavitation effects to generate deep lesions with an endocavitary applicator using a plane transducer: Ex vivo studies.

David Melodelima, Jean Yves Chapelon, Yves Theillère and Dominique Cathignol.

INSERM, Unité 556, 151 Cours Albert Thomas, 69424 Lyon, France

Corresponding author: David Melodelima

Pho. : (33) 4-72-68-19-30

Fax : (33) 4-72-68-19-31

E-mail : melodelima@lyon.inserm.fr

Running title : Combination of thermal and cavitation effects 
Combination of thermal and cavitation effects to generate deep lesions with an endocavitary applicator using a plane transducer: Ex vivo studies.

Abstract

In the HIFU field it is well known that the cavitation effect can be used to induce lesions of larger volume. The principle is based on the increase in the equivalent attenuation coefficient of the tissue in the presence of the bubbles created by cavitation. The elementary lesions produced by combination of cavitation and thermal effect, using focused transducers, were spherical and developed upstream of the focal point. This paper presents a method that combines cavitation with a thermal effect to obtain deeper lesions using a plane transducer rather than a focused one. The cavitation effect was produced by delivering intensities of $60 \mathrm{~W} / \mathrm{cm}^{2}$ at the face of the transducer for $0.5 \mathrm{~s}$. The applicator was then rotated through $90^{\circ}$ at a constant speed of between 0.5 and $1.5 \%$ s. During this rotation, ex vivo tissues were exposed continuously to an acoustic intensity of $14 \mathrm{~W} / \mathrm{cm}^{2}$ to combine the cavitation effect with a thermal effect. The necroses were on average twice as deep when the cavitation effect was used compared with those obtained with a thermal effect alone. Observed macroscopically, the lesions have a very well delimited geometry. Temperature measurements made at different angles of treatment have shown that they were coagulation necroses.

Key words: Ultrasound, thermal ablation, cavitation, endocavitary, plane transducer, high intensity ultrasound 


\section{INTRODUCTION}

High intensity ultrasound affects biological tissue by different mechanisms, the two most important of which are thermal effects and cavitation effects. The great surge in interest in HIFU (high intensity focused ultrasound) over the last ten years have led to numerous ex vivo, in vivo and clinical studies. Analysis of the damage suffered by the biological tissue has given a better understanding of the importance of the mechanisms activated in the formation of coagulation necroses (Fry et al. 1955, Hynynen et al. 1993, ter Haar et al. 1989, Chapelon et al. 1999, Chavrier et al. 2000). When tissue destruction is due to purely thermal effects, the shapes of the elementary lesions, which are very well defined and reproducible, depend on the geometry of the transducer employed. The lesions are ellipsoidal if HIFU is used (Fry et al. 1970), cylindrical for cylindrical transducers (Deardorff and Diederich 1998), or in the shape of a rectangular parallelepiped if a plane transducer is used for sonication (Lafon et al. 1999, Melodelima et al. 2003).

Numerous authors have noted the appearance of a cavitation effect leading to a change in the geometry of the necroses when the intensity of the ultrasound wave is increased (Chapelon et al. 1990, Fry 1993, Lizzi 1993, Sanghvi et al. 1995, Watkin et al. 1996). The HIFU-induced lesion grows broader, moves closer to the transducer and becomes tadpoleshaped. There are a number of therapeutic applications where it is useful to generate the cavitation effect. For instance, studies in the field of shock-wave lithotripsy (Cathignol et al. 1995, Coleman et al. 1996) have clearly demonstrated experimentally that the action of the pressure release waves on the bubbles made it possible to increase the rate at which the kidney stones are destroyed. Coleman et al. (1987) has also shown that the condensation liquid accumulated in the bubbles during the first cycles of stable cavitation is expelled as 
"microjets" as the bubbles implode. These "microjets" play a decisive part in attacking the solid/liquid interface, leading to the destruction of the stone.

When ultrasound is used for surgical applications, the effects of uncontrolled cavitation produce irregular lesions, called hemorrhagic necroses, with damage outside the target area. This point has been clearly noted by several authors (Fry et al. 1970, Sibille et al. 1993, Chapelon et al. 2000), who recommended avoiding these non-linear effects if the intention was to induce a coagulation necrosis with a well-defined geometry. Studies on gels (Holt and Roy 2001) and on ex vivo (Lele 1987, Clarke and ter Haar 1997) and in vivo (Hynynen 1991) tissue have nevertheless demonstrated that the appearance of cavitation in the tissue causes a large temperature increase, which it may be judicious to use.

These observations were the starting point for research involving the use of controlled cavitation to enlarge the dimensions of the necrosed region. For this, some authors (Brayman et al. 1995, Chang et al. 2001, Chen et al. 2003) injected contrast agents, generally used to improve the imaging, into the tissue before starting treatment. Adopting a different approach, Sokka et al. (2002) proposed emitting a very high intensity ultrasound wave (around 300 acoustic watts) of brief duration ( $0.5 \mathrm{~s})$ to generate microbubbles by cavitation. This exposure was followed immediately by a lower intensity insonification (around 20 acoustic watts) for 19.5 s. This procedure could be used to combine cavitation and the thermal effect and to induce larger necroses than those observed when no cavitation was produced. However, although the volume of such lesions was larger, this approach could not induce a necrosis beyond the focal point.

Among the explanations advanced to account for the increase in the size of the lesions, Chavrier et al. (2000) proposed that the energy absorbed by the bubbles generated during cavitation was redistributed by spherical waves, the frequencies of which corresponded to harmonics above the excitation frequency. This implied a local increase in the attenuation 
around the bubbles, which then absorbed much of the energy emitted by the transducer and prevented a deposit of heat beyond the focal area. Holt et al. (2002) proposed that the temperature increase following cavitation was due to the viscous damping between the bubbles and the tissue.

With the same idea of necrosing greater volumes, this paper presents a new approach using the cavitation effect to increase the depth of necrosis. For this, an endocavitary applicator equipped with a plane transducer is used. Cavitation is obtained with an acoustic intensity of only $60 \mathrm{~W} / \mathrm{cm}^{2}$, which is then reduced to $14 \mathrm{~W} / \mathrm{cm}^{2}$, corresponding to an energy level sufficient to create a coagulation necrosis. The aim of the tests presented in this study is to compare the size of the lesions in the presence or absence of cavitation and to ensure, by temperature measurements, that the thermal dose required for necrosis is reached over the whole of the affected depth when the cavitation effect is used.

\section{MATERIALS}

The applicator (Fig. 1) consisted of a 3.8-mm O.D. stainless steel tube with a 0.1-mm thick wall ending in a cone-shaped brass tip. The plane active surface embedded in the brass section is a $3 \times 10 \mathrm{~mm}^{2} \mathrm{P} 762$-type PZT piezoceramic air-backed transducer (Quartz \& Silice, Nemours, France) operating at 5.16 MHz. The central lumen of the tube provided electrical RF connections and a path for the cooling water. RF connections were made via a miniaturized $50 \mathrm{~cm}$ long, $50 \Omega$ coaxial cable with a $0.9-\mathrm{mm}$ O.D. The outer ground conductor was connected to the external face of the transducer. The inner conductor reached the internal face of the transducer through the lumen of the tube. The transducer was glued with Stycast 2651 epoxy resin (Emerson \& Cuming Europe n.v., Westerlo-Oevel, Belgium) to ensure that it was watertight and to hold it in place. The stainless steel tube was filled with RTV 143 
silicone (Rhône Poulenc Italia, Milano, Italy) to hold in place all the elements passing through it and so to strengthen the applicator assembly. To limit energy loss during transmission of the electric signal, a connection with a capacitor-inductor network was included to match the transducer. The inductor $(1.8 \mu \mathrm{H})$ and the capacitor $(300 \mathrm{pF})$ were placed respectively in parallel and in series with the coaxial-transducer assembly. The initial electrical impedance of the applicator $(\mathrm{Zr}=20 \Omega$ (real part of the impedance); $\mathrm{Zi}=-50 \Omega$ (imaginary part of the impedance)) measured with an HP 4285A impedance meter was $\mathrm{Zr}=50.1 \Omega$ and $\mathrm{Zi}=-3 \Omega$ after electrical matching. The reflected power was then close to zero. Using the acoustic balance technique (Davidson 1991), the electroacoustic efficiency of the applicator was measured to $65 \%$ at $5.16 \mathrm{MHz}$.

The external face of the transducer was cooled by a continuous flow of degassed water circulating the length of the transducer. The water cooling circuit was maintained at $25^{\circ} \mathrm{C}$ and was driven by a Masterflex peristaltic pump (Cole Parmer Instrument Co., Chicago, USA) at a flow of $0.15 \mathrm{~L} \cdot \mathrm{min}^{-1}$. The temperature of the active face was maintained at about $45^{\circ} \mathrm{C}$ during sonication. By adjusting the cooling flow, the maximum temperature may be slightly shift away from the applicator surface, thereby increasing the depth of therapeutic heating (Deardorff and Diederich 2000). The applicator was fixed on a PVC support (Fig. 2) and its position was controlled by a motion stage with a control unit (Microcontrol ITL09, Newport Corporation, Irvine, CA). Three types of movement were possible: horizontally, vertically along the applicator axis and rotationally around the applicator axis. Electrical energy was supplied by a Kalmus $150 \mathrm{CF}$ amplifier (Engineering International, Woodinville, WA) driven by a HP $8116 \mathrm{~A}$ sine wave generator (HP GmbH, Böblinger, Germany). Incident and reflected power were measured using a wattmeter/reflectometer (Rohde \& Schwarz, Munich, Germany) at the amplifier output. The function generator and the position controller were piloted by a computer using the Testpoint software (CEC, Billeria, Massachusetts, USA). The 
system enabled the amplitude, duration of exposures and angle of treatment of the sonications to be programmed. A Hawk 2102 XDI ultrasound scanner (B-K Medical, Norderstedt, Germany) and an imaging probe operating at $12 \mathrm{MHz}$ with a linear array were used to visualize the cavitation inside the tissue.

\section{METHOD}

All tests were performed ex vivo on 43 parallelepiped-shaped samples $\left(100 \times 100 \times 30 \mathrm{~mm}^{3}\right)$ of pig's liver. The time between the animal's slaughter and the use of its liver was unknown, so each sample was degassed with a vacuum pump ( 0.7 bars for $30 \mathrm{~min}$ ) before the experiment to remove any bubbles that might have formed during storage and thus reproduce in vivo conditions more closely. The samples were then immersed in a tank of degassed water thermostatically maintained at $37^{\circ} \mathrm{C}$. A thermocouple was inserted in each sample to ensure that the temperature was close to $37^{\circ} \mathrm{C}$ before starting exposure. A hole was punched in the middle of each sample attached to a PVC support (Fig. 2). The flow of degassed water used to cool the transducer was set to $0.15 \mathrm{~L} / \mathrm{min}$.

Determination of the cavitation threshold.

A first series of tests was conducted to determine the acoustic intensity threshold from which the applicator would produce the cavitation effect if the exposure time was $0.5 \mathrm{~s}$. The acoustic intensities tested to determine the threshold were $30,40,50,60$ and $80 \mathrm{~W} / \mathrm{cm}^{2}$. During these exposures, cavitation was detected with the $12 \mathrm{MHz}$ ultrasound imaging probe positioned perpendicularly to the applicator (Fig. 3). 
A second series of tests was conducted to show that the cavitation produced in this way could be useful to increase the depth of the necroses. Two elementary lesions were produced on three liver samples. The first elementary lesion (lesion A), regarded as a reference, was induced by exposing the tissues to an acoustic intensity of $14 \mathrm{~W} / \mathrm{cm}^{2}$ for $20 \mathrm{~s}$. These parameters are known to induce coagulation necroses by purely thermal effect (Lafon et al. 1998). The second elementary lesion (lesion B) was produced by first performing a 0.5s. exposure at an acoustic intensity of $60 \mathrm{~W} / \mathrm{cm}^{2}$, followed immediately afterwards by a 20 -s exposure at $14 \mathrm{~W} / \mathrm{cm}^{2}$. The aim of this methodology was to determine the contribution of the cavitation generated by the short high intensity exposure in terms of increased depth of necrosis. Three samples were used during this experiment to ensure the reproducibility of the results.

\section{Comparison of the depth of sector-based lesions with and without cavitation}

A final series of tests was conducted on 32 samples to see whether the size of the lesions could be increased by combining the cavitation and the thermal effect even when the applicator was rotated on its axis through angular openings of $90^{\circ}$. Four different rotation speeds were tested: $0.5,0.8,1$ and $1.5 \%$. Four reference groups (one for each rotation speed tested), each consisting of three samples, were treated at an acoustic intensity of $14 \mathrm{~W} / \mathrm{cm}^{2}$ emitted continuously during rotation (sequence 1 see figure 4a). These groups of samples were used to determine the depth of the necroses induced by a purely thermal effect. Three samples were used for each rotation speed tested to ensure the reproducibility of the results. Then the cavitation effect was combined with the thermal effect, using a group of 20 samples. 
For this procedure, four groups (one for each rotation speed tested) of five samples were used, with the same four rotation speeds as before $(0.5,0.8,1$ and $1.5 \%$ s). Five samples were used for each set of parameters tested to ensure the reproducibility of the results. On these twenty samples, the cavitation effect was always produced with a $0.5-\mathrm{s}$ exposure at $60 \mathrm{~W} / \mathrm{cm}^{2}$. Immediately afterwards, the ultrasound applicator was rotated through $90^{\circ}$ and a thermal effect was produced by a continuous emission at $14 \mathrm{~W} / \mathrm{cm}^{2}$ during the rotation (sequence 2) to overlap the previous (Fig. 4b). Temperature measurements were realized when these sectorbased lesions were created. Four T-type thermocouples were used to determine the maximum temperature elevation at four different positions: $2.5,5.0,10.0$ and $15.0 \mathrm{~mm}$ along the axis of acoustic propagation. The temperature was measured along the axis of propagation immediately after production of the cavitation effect alone. The temperature was also measured at three angular openings $\left(30,60\right.$ and $\left.90^{\circ}\right)$ along the axis of propagation for all rotation speeds tested. The thermocouples were fitted into $0.7-\mathrm{mm}$ external diameter needles and glued in position, with their active extremity projecting $2 \mathrm{~mm}$ beyond the needle. Thanks to this reinforcement of their mechanical structure, they could be introduced as far as the measurement point without being subject to any major mechanical constraints that might lead to their destruction. To avoid interference with the ultrasound and giving inaccurate results, they were inserted into the tissue immediately after sonication. The four thermocouples were fixed to a PVC support so that they could be introduced simultaneously and provide sets of linked results. They were connected to HI 9351 digital thermometers (Hanna Instruments, Tanneries, France), which stored the maximum temperature values between resets. Measurements were made both on the samples treated by sequence 1 and on those treated by sequence 2 . The computer piloting the signal generation device controlled the power values transmitted and reflected to the transducer and stored the values delivered during each treatment. 
The liver samples were frozen immediately after treatment to make the tissue easier to section and examine. When the tissue temperature was close to $-6^{\circ} \mathrm{C}$, the sample was sliced along a plane perpendicular to the applicator axis at mid-height from the transducer. Lesions were inspected macroscopically. Coagulated and untreated tissue is easy to distinguish in pig's liver as the former is off-white in colour or even dark, like cooked liver, at the hottest points. Two axes issuing from the centre of the applicator and touching the outer edges of the lesion were used to assess the value of the angular section of the necrosis.

\section{RESULTS}

\section{Determination of the cavitation threshold}

Figure 5a shows a sonogram of the experimental set up used to detect the cavitation effect in the tissue. The ultrasound applicator can be seen positioned opposite a piece of liver. The position of the treatment transducer (grey rectangle) and the acoustic propagation axis (white narrow) are indicated in this figure. Because the body of the applicator was made of stainless steel the long rectangular hyperechogenic area located downstream of the transducer corresponds to an imaging artifact. Figure $5 \mathrm{~b}$ is a sonogram obtained immediately after performing a 0.5 -s ultrasound exposure at an acoustic intensity of $60 \mathrm{~W} / \mathrm{cm}^{2}$ in the tissue. Hyperechogenic points appear along the acoustic axis and correspond to the cavitation phenomenon induced by this exposure. The tests conducted with acoustic intensities of below $60 \mathrm{~W} / \mathrm{cm}^{2}$ did not show the appearance of cavitation. The experiments carried out with acoustic intensities of $80 \mathrm{~W} / \mathrm{cm}^{2}$ for $0.5 \mathrm{~s}$ show images similar to those in Fig. $5 \mathrm{~b}$.

Comparison of the depth of elementary lesions with and without cavitation 
All the lesion shapes were reproducible. Figure 6 shows two elementary lesions. The coagulation necrosis furthest to the right (lesion A) was induced following a 20-s exposure ultrasound exposure performed at an acoustic intensity of $14 \mathrm{~W} / \mathrm{cm}^{2}$. This was a reference lesion obtained by a purely thermal effect and measuring $10 \mathrm{~mm}$ in depth and $3 \mathrm{~mm}$ in width. The height of this lesion $(10 \mathrm{~mm})$ is the same as the height of the transducer. The second coagulation necrosis (lesion B), directed upwards, was $18 \mathrm{~mm}$ deep, $3 \mathrm{~mm}$ wide and $11 \mathrm{~mm}$ high. It was induced following a 0.5 -s exposure at an acoustic intensity of $60 \mathrm{~W} / \mathrm{cm}^{2}$ generating cavitation in the tissue, immediately followed by 20 -s exposure at an acoustic intensity of $14 \mathrm{~W} / \mathrm{cm}^{2}$ to combine the cavitation with a thermal effect.

\section{Comparison of the depth of sector-based lesions with and without cavitation}

All the lesion shapes were reproducible. The cuts made it possible to measure the depth and the treated angular opening. Figure 7 shows a reference sample treated with the sequence 1. In this case, coagulation necrosis was induced by a purely thermal effect. The depth of necrosis at the start of rotation was $4 \mathrm{~mm}$. The depth of treatment was slightly greater at the end of rotation and measured $5 \mathrm{~mm}$. The angle treated was on average $82^{\circ}$ for all samples. A brown spot appeared at the centre of the necrosis. Figure 8a shows a sample treated by the combination of cavitation and thermal effects (sequence 2) for a rotation speed set to $0.5^{\circ} / \mathrm{s}$. The angular opening treated was $79^{\circ}$. The depth of treatment was $15 \mathrm{~mm}$. The depth of treatment was not as great at the start of rotation $(13 \mathrm{~mm})$. Figure 9 a shows the geometry of the lesions obtained using sequence 2 when the applicator was rotated at a speed of $0.8^{\circ} \mathrm{s}$. This figure shows a necrosis extending over an angular opening of close to $90^{\circ}$. The edges of the lesion are distinct and very well delimited. The depth of treatment was constant 
over the whole of the necrosed region and measured $12 \mathrm{~mm}$. A few circular spots of approx. 1- to 2-mm in diameter can also be distinguished in this figure, deeper in the treated area.

Figures 10a and 11a show the lesions obtained using sequence 2 when the applicator was rotated at a speed of 1 and $1.5 \%$ s respectively. The depth of treatment was constant over the whole of the necrosed region, measuring on average $11 \mathrm{~mm}$. Figures $8 \mathrm{~b}, 9 \mathrm{~b}, 10 \mathrm{~b}$ and $11 \mathrm{~b}$ show the temperature measurements made along the acoustic axis at different treatment angles. The black line curves correspond to the exposures performed by combining the cavitation effect and the thermal effect. The gray line curves correspond to the same measurements when only the thermal effect was produced. In all cases, the temperature increase induced by thermal effect alone was less than that induced by combination of the cavitation effect and the thermal effect. Table 1 shows the means and standard deviations of temperature in the tissue when only the cavitation was produced. The gain due to cavitation was about $14^{\circ} \mathrm{C}$ for the surface of the samples and around $5^{\circ} \mathrm{C} 15 \mathrm{~mm}$ from the surface of the liver. Figure 12 compares the therapeutic depth obtained with and without cavitation when elementary lesions were created (rotation speed equal to 0 ) and for the different rotation speeds tested. All samples treated by combination of the cavitation effect and the thermal effect had deeper lesions than the ones treated only by thermal effect Table 2 compares the depths of necrosis obtained and the angular openings treated with or without the cavitation effect according to the four rotation speeds used $\left(0.5,0.8,1\right.$ and $\left.1.5^{\circ} / \mathrm{s}\right)$.

\section{DISCUSSION}

Determination of the cavitation threshold 
All these results clearly show that the depth of the lesions can be increased significantly when the cavitation effect and the thermal effect were combined judiciously. The sonograms (Fig. 5a and 5b) confirm that a $0.5-\mathrm{s}$ exposure of $60 \mathrm{~W} / \mathrm{cm}^{2}$ was sufficient to induce the cavitation effects in the tissue with the applicator used. This acoustic intensity value corresponds to a threshold as cavitation was not detected for values of below $60 \mathrm{~W} / \mathrm{cm}^{2}$, using the proposed method.

\section{Comparison of the depth of elementary lesions with and without cavitation}

The elementary lesions performed ex vivo made it possible to assess the contribution of this cavitation in terms of depth of treatment when combined with a thermal effect (Fig. 6). Lesion A was the product of $14 \mathrm{~W} / \mathrm{cm}^{2}$ during 20 seconds $\left(280 \mathrm{~J} / \mathrm{cm}^{2}\right)$. Lesion B was the product of $60 \mathrm{~W} / \mathrm{cm}^{2}$ during 0.5 seconds combined with $14 \mathrm{~W} / \mathrm{cm}^{2}$ during 20 seconds (310 $\mathrm{J} / \mathrm{cm}^{2}$ ). The depth of treatment was $10 \mathrm{~mm}$ with the exposure involving thermal effect alone and $18 \mathrm{~mm}$ through the combination of cavitation and thermal effect. Thus, it was clearly shown that the exposition producing lesion B has appreciable effect only through cavitation. In the tests conducted using intensities of below $60 \mathrm{~W} / \mathrm{cm}^{2}$, the size of the lesions was not increased as the cavitation threshold was not reached at these intensities. A greater intensity $\left(80 \mathrm{~W} / \mathrm{cm}^{2}\right)$ causes cavitation over an ever large spatial region but the following exposure at $14 \mathrm{~W} / \mathrm{cm}^{2}$ does not deposit enough energy in depth to induce a coagulation necrosis. Mainly because the beam was greatly attenuated and was divergent beyond $18 \mathrm{~mm}$ in depth.

Comparison of the depth of sector-based lesions with and without cavitation 
The reference samples treated with sequence 1 showed a necrosis over a smaller angular region than the exposure angle $\left(82^{\circ}\right.$ instead of $\left.90^{\circ}\right)$, even though rotation was piloted precisely by the microcontroller drive unit. This difference can be explained by an amount of heat that was insufficient to reach the thermal dose required to induce a necrosis in the tissue over the first few degrees. As there is no perfusion ex vivo a phenomenon of thermal build up causes an important amount of heat at the end of the rotation. Thus, The depth of treatment was slightly less at the start $(4 \mathrm{~mm})$ than at the end of exposure $(5 \mathrm{~mm})$. This can be avoided if the applicator is rotated through more than $360^{\circ}$ so as to pass over a second time the first areas treated or by using a lower rotation speed at the start of treatment.

All samples treated by combination of the cavitation effect and the thermal effect had deeper lesions than the ones treated only by thermal effect (Fig. 12). When the rotation speed was slower $(0.5 \%$ s), the depth of the necrosis (Fig. 8) was around $15 \mathrm{~mm}$ and slightly less at the start of rotation (approx. $13 \mathrm{~mm}$ ). This is explained by a phenomenon of heat diffusion and accumulation at the end of treatment. When the rotation speed increased (as from $0.8 \%$ ), the lesions were distributed over $90^{\circ}$ with a constant depth of 11 to $12 \mathrm{~mm}$. A clear and very well delimited boundary was then visible between the necrosed and the healthy areas. The existence of the cavitation effect is illustrated in Fig. 9 by the appearance of small circular lesions of about 1 to $2 \mathrm{~mm}$ in diameter. These are small necrosis spots induced by the large temperature increases following implosion of the bubbles present in the tissue. These small necrosed spots appear not only at the start of rotation but are scattered randomly at depth through the whole of the treated angular opening.

There were no significant differences between the lesions produced using rotation speeds of 1 or $1.5 \%$ and those produced with a rotation speed of $0.8 \%$, as is shown by Fig. 9, 10 and 11 , corresponding to angular speeds of $0.8,1$ and $1.5 \%$ s respectively. This speed thus appears to be the threshold for making it possible to benefit from the cavitation effect 
produced by the first high intensity exposure and to induce lesions homogeneous in depth and with a distinct geometry. The method presented in this work makes it possible to necrose cylindrical volumes of $31.4 \mathrm{~cm}^{3}$ in 4 minutes if the rotation speed is $1.5^{\circ} / \mathrm{s}$ or volumes of $70.6 \mathrm{~cm}^{3}$ in 12 minutes if the rotation speed is $0.5^{\circ} / \mathrm{s}$.

The sequences of conventional ultrasound exposures consist of performing a sonication in one direction then of interrupting exposure while the applicator is moved, thus halting the cavitation effect. In this study, the cavitation was combined with a classical thermal effect without interrupting the exposure during the rotation of the applicator. This approach making it possible to maintain the cavitation as indicated by the homogeneity of the depths of necrosis.

The many tests conducted in the HIFU field have demonstrated that when the intensity of the acoustic wave is very high (over $700 \mathrm{~W} / \mathrm{cm}^{2} / \mathrm{MHz}$ (Hynynen 1991)), unstable cavitation appears and participates in cell destruction at the focal point, but in a totally unpredictable manner. At the same time, the microbubbles generated by cavitation can be regarded as secondary diffusing sources. It has been shown that the acoustic energy stored in a resonant bubble is redistributed in the form of a wave the high harmonics of which are rapidly absorbed in the tissue. The bubbles formed in the conical prefocal zone of the ultrasound field help to absorb much of the energy. Beyond the focal point, the energy is so attenuated that no lesion is created. The shape of the lesion becomes more spherical and moves closer to the face of the transducer. Its dimensions are much larger than they would have been through a purely thermal effect.

The originality of the present study has been to demonstrate that the propagation of the ultrasound beam ceases to be greatly attenuated by the presence of the cavitation previously described but that a phenomenon of complex diffusion makes it possible to increase the depth over which the energy is deposited. When the cavitation effect is produced during HIFU 
treatments to destroy tumours, the main disadvantage is lack of control of the damage induced. The effects associated with cavitation (microjets, high pressure, high temperature) frequently cause damage outside the target region or fail to denature the proteins that are small DNA sequences of the tumour cells. These sequences are liable to graft themselves onto healthy cells belonging to other organs and hence routes the appearance of a new tumour mass (Prat et al. 1991). The temperature measurements made during this study (Fig. 8b, 9b, 10b and 11b) were all above $60^{\circ} \mathrm{C}$ after exposures of several seconds for all the region treated. This implies that, the thermal dose required to produce a coagulation necrosis, was reached over depths that correspond to the macroscopically visible affected area. Likewise, these curves make it possible to measure the importance of the cavitation phenomenon in terms of heat contribution along the acoustic axis. Our method may be envisaged for treating cancers developing in the lumen of the digestive tract to destroy the tumour definitively and irreversibly by coagulation necrosis, if the diameter of these tumours is slightly less than the treated depth. To increase the depth of treatment, it might appear natural and simpler to reduce the working frequency of the transducer to provide greater penetration of the ultrasound beam into the tissue. However with miniature endocavitary applicators like the one presented in this work this idea has a major disadvantage, as the small dimensions of the transducer mean that the ultrasound beam very rapidly becomes divergent. This makes it very difficult to deposit energy at depth to induce a necrosis of equivalent dimensions to those presented in this study. Furthermore, the results of this method can have a wide range of extremely promising applications if they are employed to destroy large excrescences accessible by endocavitary or coelioscopic route when these ensue from a benign pathology. 


\section{REFERENCES}

Brayman A.A., Azadniv I.R.S., Makin M.W., Carstensen E.L., Child S.Z., Raeman R.S., Meltzer R.S. and Everbach E.C. Effect of a stabilized microbubble contrast agent on hemolysis of human erythrocytes exposed to high-intensity pulsed ultrasound. Echocardiography. 1995;12(12):13-22.

Cathignol D., Birer A., Nachef S. and Chapelon J.Y., Electronic beam steering of shock waves. Ultrasound Med. Biol. 1995;21: 365-377.

Chang P.P., Chen W., Mourad P.D., Poliachik S.L. and Crum L.A. Thresholds for inertial cavitation in Albumex Suspensions under pulsed ultrasound conditions. IEEE UFFC. 2001;48(1):161-170.

Chapelon J.Y., Margonari J., Cathignol D., Gelet A., Guers C. and Theillère Y. Threshold for tissue ablation by focused ultrasound. IEEE Ultrason Symp 1990;90CH2938-9:1653-1656.

Chapelon J.Y., Ribault M., Vernier F., Souchon R. and Gelet A. Treatment of localised prostate cancer with transrectal high intensity focused ultrasound. European Journal of Ultrasound: 1999;9:31-38.

Chapelon J.Y., Cathignol D., Cain C., Ebbini E., Kluiwstra J.U., Sapozhnikov O.A., Fleury G., Berriet R., Chupin L., Guey J.L. New piezoelectric transducers for therapeutic ultrasound. Ultrasound Med. Biol. 2000;26:153-159. 
Chavrier F., Chapelon J.Y., Gelet A. and Cathignol D. Modeling of high-intensity focused ultrasound-induced lesions in the presence of cavitation bubbles. J. Acoust. Soc. Am. 2000;108(1):432-440.

Chen W.S., Lafon C., Matula T.J., Vaezy S and Crum LA. Mechanisms of lesion formation in high intensity focused ultrasound therapy. Acoustics Research Letters Online. 2003, 4(2):4146

Clarke R.L. and ter Haar G.R. Temperature rise recorded during lesion formation by highintensity focused ultrasound. Ultrasound Med. Biol. 1997;23:299-309.

Coleman A.J., Saunders J.E, Crum L.A. and Dyson M. Acoustic cavitation generated by an extracorporeal shockwave lithotriter. Ultrasound Med. Biol. 1987;13:69-76.

Coleman A.J., Choi M.J., Saunders J.E. Detection of acoustic emission from cavitation in tissue during clinical extracorporeal lithotripsy. Ultrasound Med. Biol. 1996;22:1079-1087.

Davidson F. Ultrasonic power balances. In Preston R.C., Output measurements for medical ultrasound, Springer Verlag, Berlin, Germany, 1991;75-90.

Deardorff D.L. and Diederich C.J., Interstitial ultrasound applicators with internal cooling for controlled high temperature thermal therapy, in IEEE Ultrason. Symp., Sendai, Japan, 1998, pp. 1541-1545. 
Deardorff D.L. and Diederich C.J., Ultrasound Apllicators with Internal Water-Cooling for High-Powered Interstitial Thermal Therapy. IEEE Transactions on Biomedical Engineering. 2000;47(10):1356-65.

Fry W.J., Barnard J.W., Fry F.J. et al. Ultrasonically produced localized selective lesions in the central nervous system. Am. J. Phys. Med. 1955;34:413-423.

Fry F.J., Kossof G., Eggleton R.C., Dunn F. Threshold ultrasonic dosages for structural changes in the mammalian brain. J. Acoust. Soc. Am. 1970;48:1413-1417.

Fry F.J. Intense focused ultrasound in medicine. Eur. Urol. 1993;23:2-7.

Holt R.G. and Roy R.A. Measurements of bubble-enhanced heating from focused, MHzfrequency ultrasound in a tissue-mimicking material. Ultrasound in Med. \& Biol. 2001;27:1399-1412.

Holt R.G., Roy R.A., Edson P.A. and Tang X. Bubbles and HIFU: The good, the bad and the ugly. ISTU Symposium, Seattle USA, 2002 at press.

Hynynen K. The threshold for thermally significant cavitation in dog's thigh muscle in vivo. Ultrasound in Med. \& Biol., 1991;17:157-169.

Hynynen K., Darkazanli A., Unger E., Schenk J.F. MRI-guided noninvasive ultrasound surgery. Med. Phys. 1993;20:107-115. 
Hynynen K., Jolesz F. Demonstration of potential noinvasive ultrasound brain therapy through an intact skull. Ultrasound Med. Biol. 1998;24:275-283.

Lafon C., Chapelon J.Y., Prat F., Gorry F., Margonari J., Theillère Y. and Cathignol D. Design and preliminary results of an ultrasound applicator for interstitial thermal coagulation. Ultrasound in Med. \& Biol., 1998;24(1):113-122.

Lafon C., Prat F., Arefiev A., Theillère Y., Chapelon J.Y., Cathignol D. Ultrasound Interstitial Applicator for Digestive Endoscopy: In Vivo Destruction of Biliary Tissues. IEEE Ultrasonics Symposium in Lake Tahoe, USA 1999;2:1447-1450.

Lele PP. Effects of ultrasound on solid mammalian tissues and tumors in vivo. In: Repacholi MH, Grandolfo M., Rindi A., eds. Ultrasound: Medical applications, biological effects and hazard potential. New York: Plenum, 1987:275-306.

Lizzi F.L. High-precision thermotherapy for small lesions. Eur. Urol. 1993;23:23-28.

Melodelima D., Lafon C., Prat F., Theillère Y., Arefiev A. and Cathignol D. Transesophageal Ultrasound Applicator for Sector-Based Thermal Ablation: First in vivo Experiments. Ultrasound in medicine and biology 2003;29(2):285-291.

Prat F., Ponchon T., Berger F., Chapelon J.Y., Gagnon P. and Cathignol D. Hepatic lesions in the rabbit induced by acoustic Cavitation. Gastroenterology 1991;100:1345-1350. 
ter Haar G., Sinnett D., Rivens I. High-intensity focused ultrasound -a surgical technique for the treatment of discrete tumours. Phys. Med. Biol. 1989;23:107-115.

Sanghvi N.T., Fry F.J., Bihrle R. et al. Microbubbles during tissue treatment using high intensity focused ultrasound. IEEE 95 UFFc symposium 1995:1249-1253.

Sibille A., Prat F., Chapelon J.Y., El Fadil F.A., Henry L., Theillere Y., Ponchon T. and Cathignol D. Characterization of extracorporeal ablation of normal and tumor-bearing liver tissue by high-intensity focused ultrasound. Ultrasound Med. Biol. 1993;19:803-813.

Sokka S., King R. and Hynynen K. Gas bubble enhanced ultrasound heating in in vivo rabbit thigh. IEEE Ultrasonics Symposium, Munich Germany 2002 In press.

Watkin N.A., ter Haar G.R., Rivens I. The intensity dependence of the site of maximal energy deposition in focused ultrasound surgery. Br. J. Urol. 1995;75(Suppl. 1):1-8. 


\section{Figure Caption}

Fig. 1: Schematic drawing of the ultrasound applicator.

Fig. 2: Wiring system and electrical equipment for ex vivo experiments and temperature measurements.

Fig. 3: Schematic drawing of the experimental set up during the acquisition of sonograms.

Fig. 4: (a) Sequence 1 applied to produce sector based lesion only by thermal effect. (b) Sequence 2 applied to produce sector based lesions by combining cavitation and thermal effect.

Fig. 5: (a) Sonogram of the experimental device in front of a liver sample. (b) Sonogram realised on the same sample just after an ultrasound exposure of $60 \mathrm{w} / \mathrm{cm}^{2}$ during half a second. The bubbles created by cavitation appears in hypersignal along the acoustic axis.

Fig. 6: Two elementary lesions. The lesion located at the right (lesion A) was performed by an ultrasound exposure of $14 \mathrm{w} / \mathrm{cm}^{2}$ during $20 \mathrm{~s}$. The lesion located at the top (lesion B) was induced by an ultrasound exposure of $60 \mathrm{~W} / \mathrm{cm}^{2}$ during half a second, then an exposure was performed at $14 \mathrm{~W} / \mathrm{cm}^{2}$ during $20 \mathrm{~s}$.

Fig. 7: Coagulation necroses created by sequence 1 . The rotation speed was set to $1 \%$ s. 
Fig. 8: (a) Coagulation necroses created by sequence 2 . The rotation speed was set to $0.5^{\circ} \mathrm{s}$.. (b) Temperature was measured at $30^{\circ}(\boldsymbol{\square}), 60^{\circ}(\mathbf{\Lambda})$ and $90^{\circ}(\bullet)$ when cavitation and thermal effects were produced (black curves) and without generating cavitation (grey curves).

Fig. 9: (a) Coagulation necroses created by sequence 2 . The rotation speed was set to $0.8 \%$ s. (b) Temperature was measured at $30^{\circ}(\mathbf{\square}), 60^{\circ}(\mathbf{\Lambda})$ and $90^{\circ}(\bullet)$ when cavitation and thermal effects were produced (black curves) and without generating cavitation (grey curves).

Fig. 10: (a) Coagulation necroses created by sequence 2 . The rotation speed was set to $1 \%$ s. (b) Temperature was measured at $30^{\circ}(\boldsymbol{\square}), 60^{\circ}(\mathbf{\Delta})$ and $90^{\circ}(\bullet)$ when cavitation and thermal effects were produced (black curves) and without generating cavitation (grey curves).

Fig. 11: (a) Coagulation necroses created by sequence 2 . The rotation speed was set to $1.5 \%$ s. (b) The temperature was measured at $30^{\circ}(\mathbf{\square}), 60^{\circ}(\mathbf{\Delta})$ and $90^{\circ}(\bullet)$ when cavitation and thermal effects were produced (black curves) and without generating cavitation (grey curves).

Fig. 12: Therapeutic depth versus the rotation speed with and without cavitation. The depth of the elementary lesions (produced by $14 \mathrm{~W} / \mathrm{cm}^{2}$ during 20 seconds with and without cavitation) was also included (rotation speed $=0 \%$ s) 


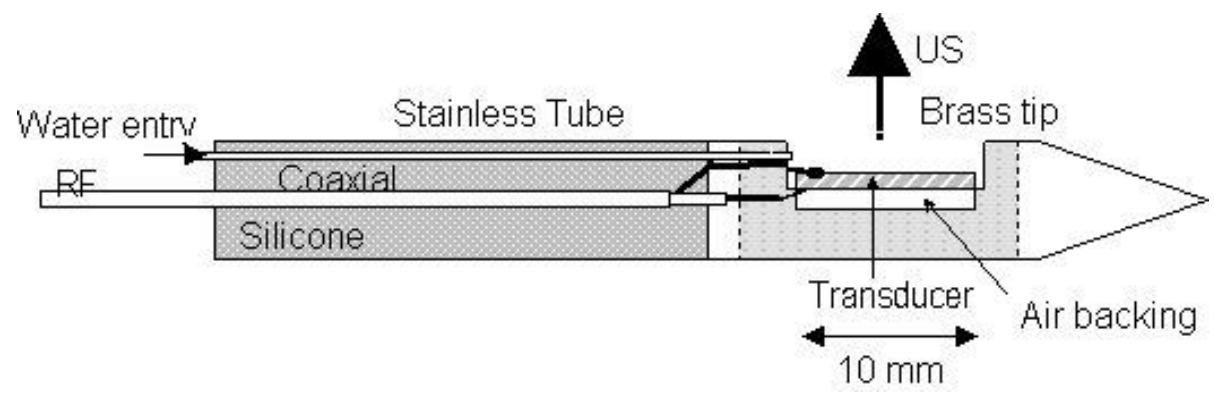

Figure 1 - D. Melodelima 


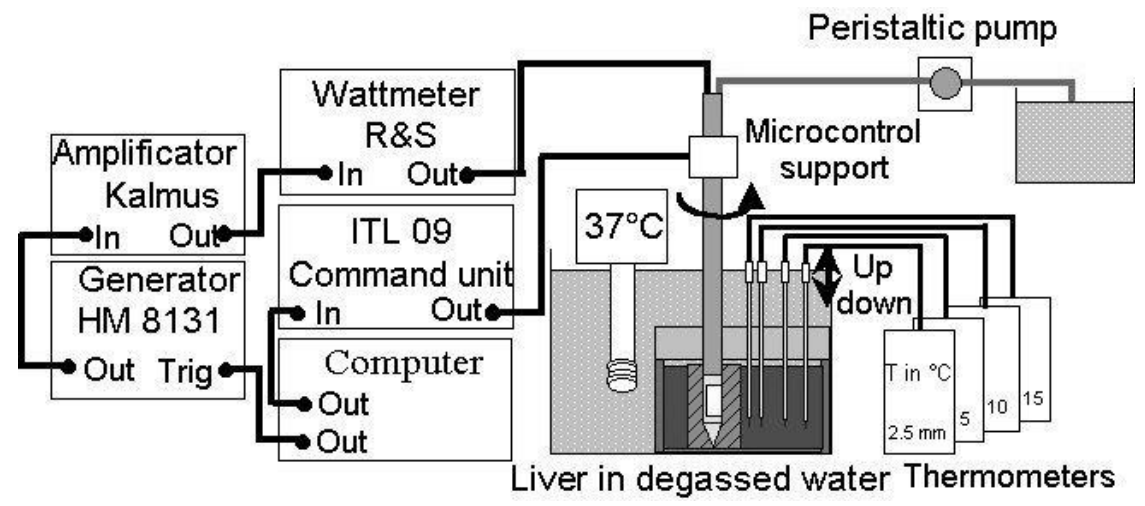

Figure 2-D. Melodelima 


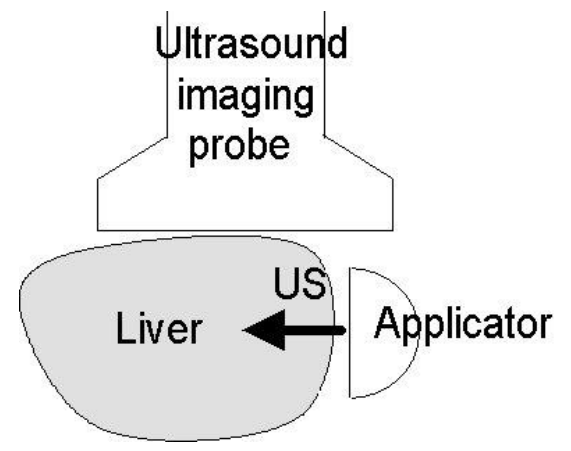

Figure 3 - D. Melodelima 


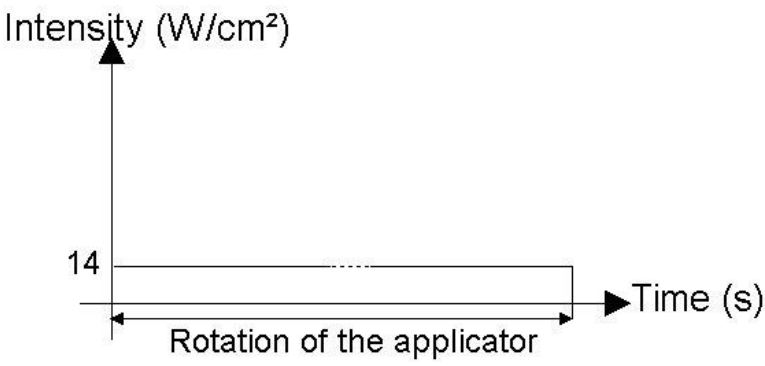

(a)

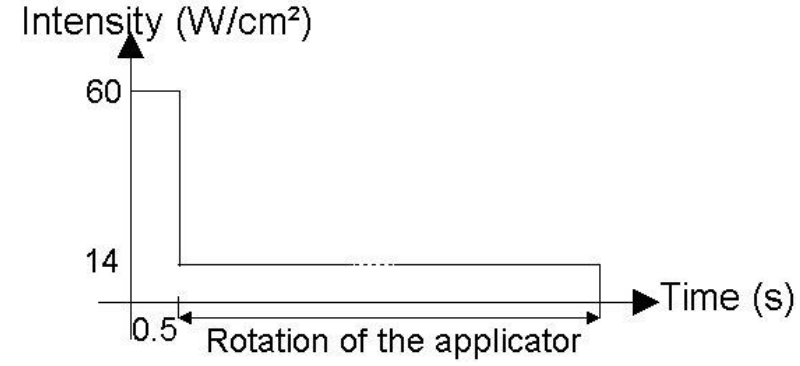

(b)

Figure 4 - D. Melodelima 


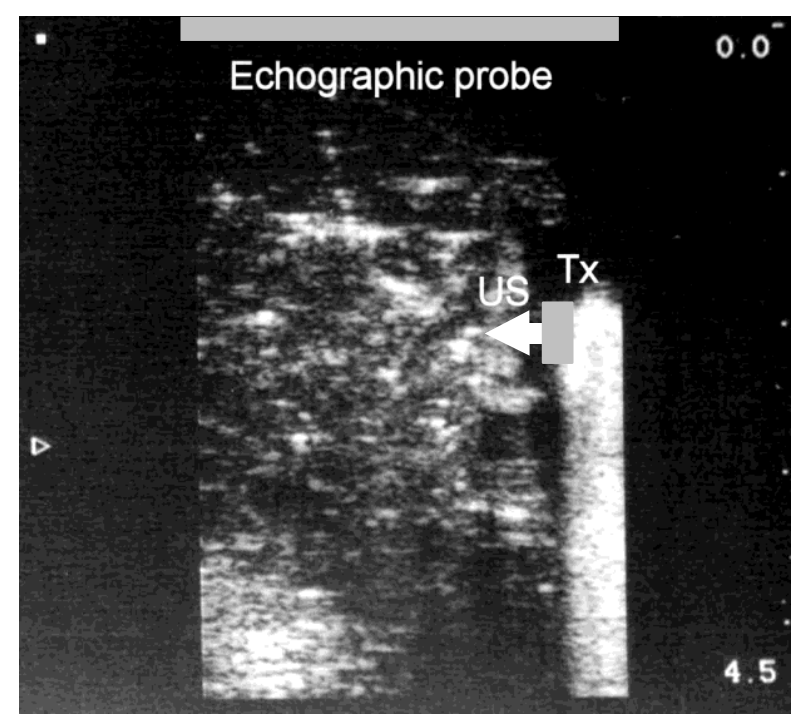

(a)

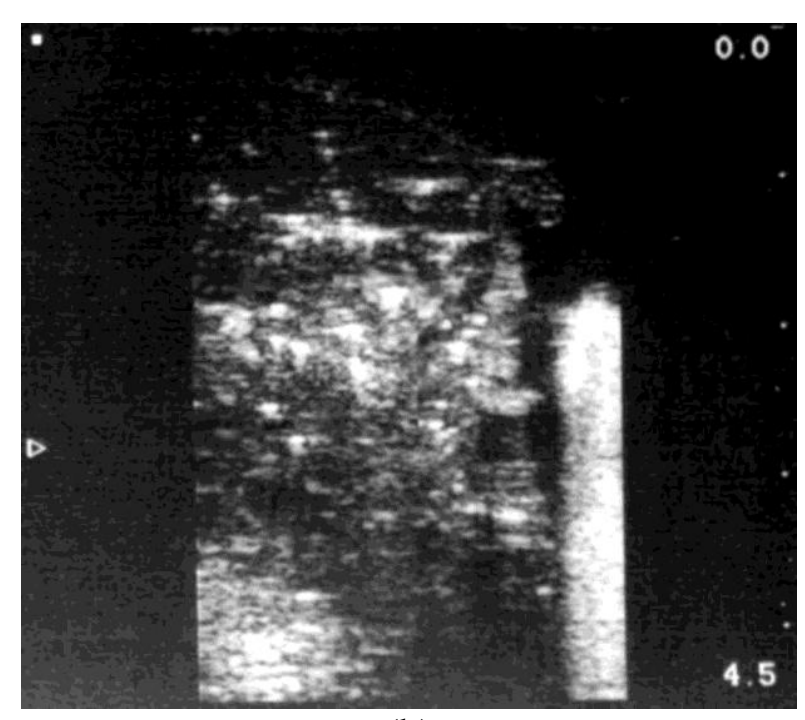

(b)

Figure 5-D. Melodelima 


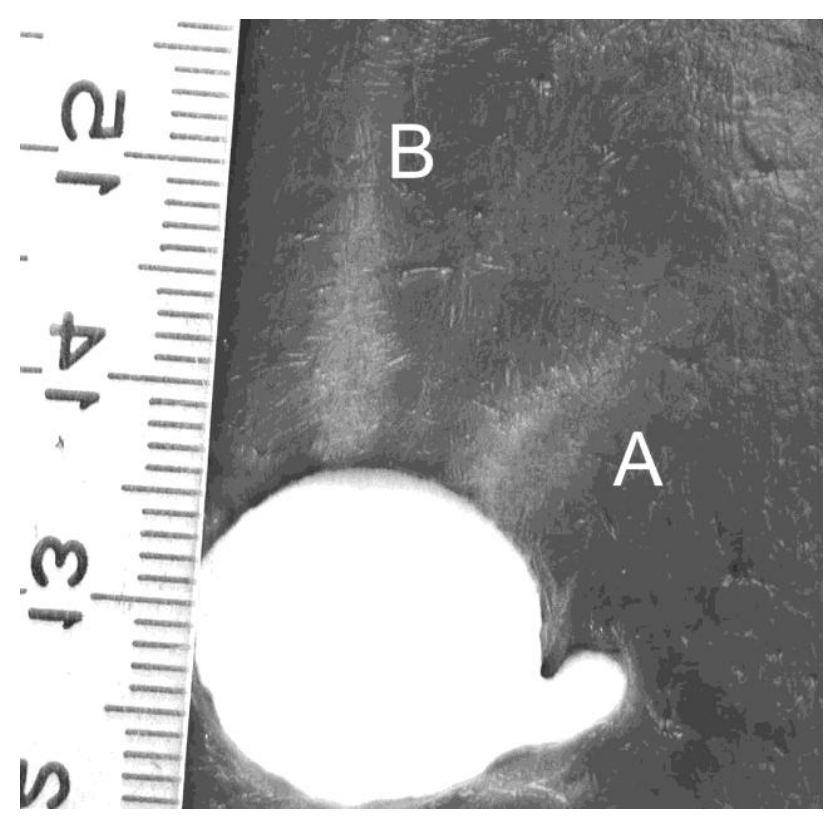

Figure 6 - D. Melodelima 


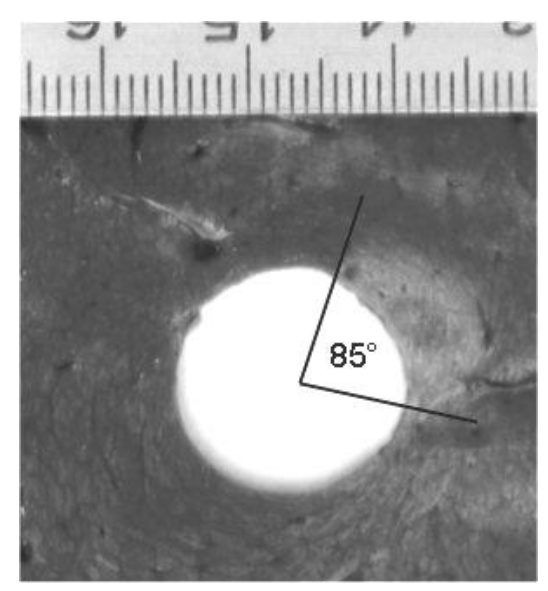

Figure 7 - D. Melodelima 

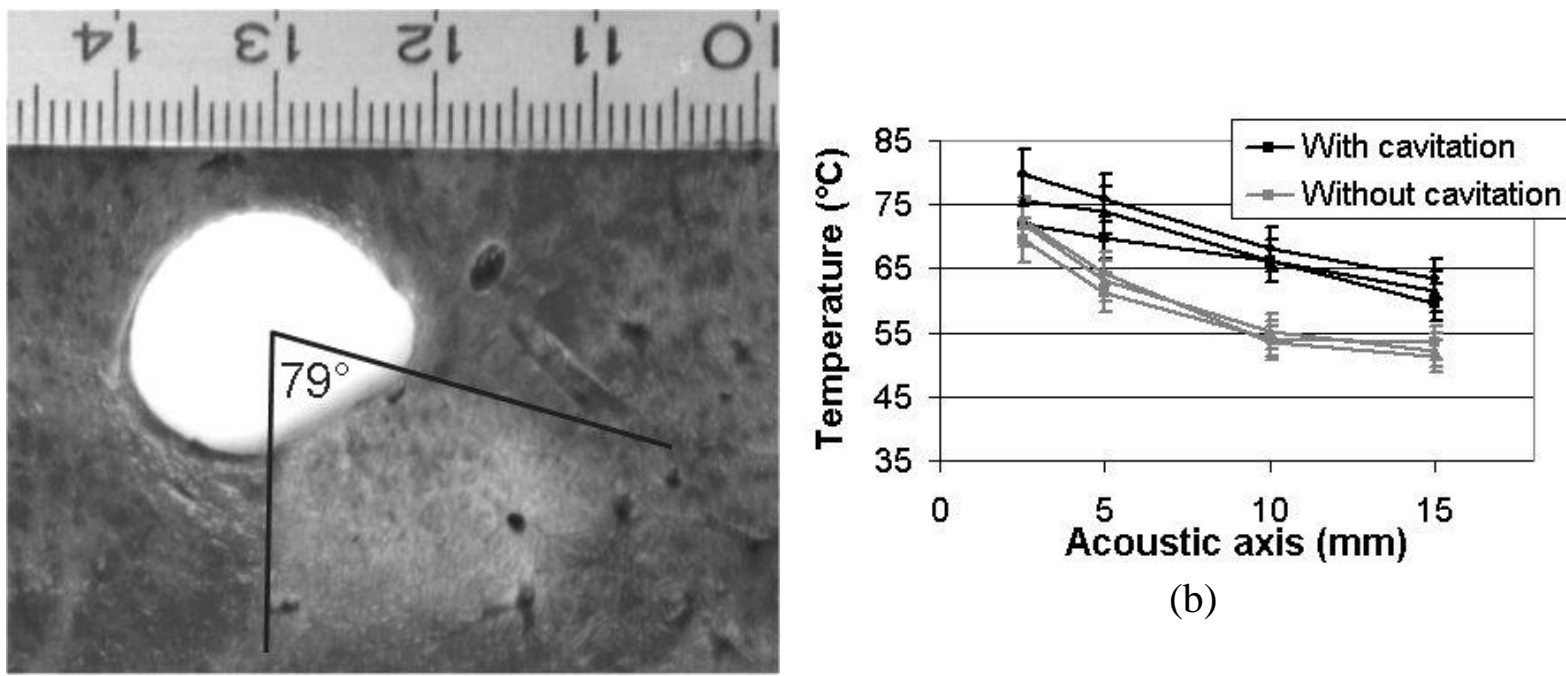

(a)

Figure 8 - D. Melodelima

(b) 

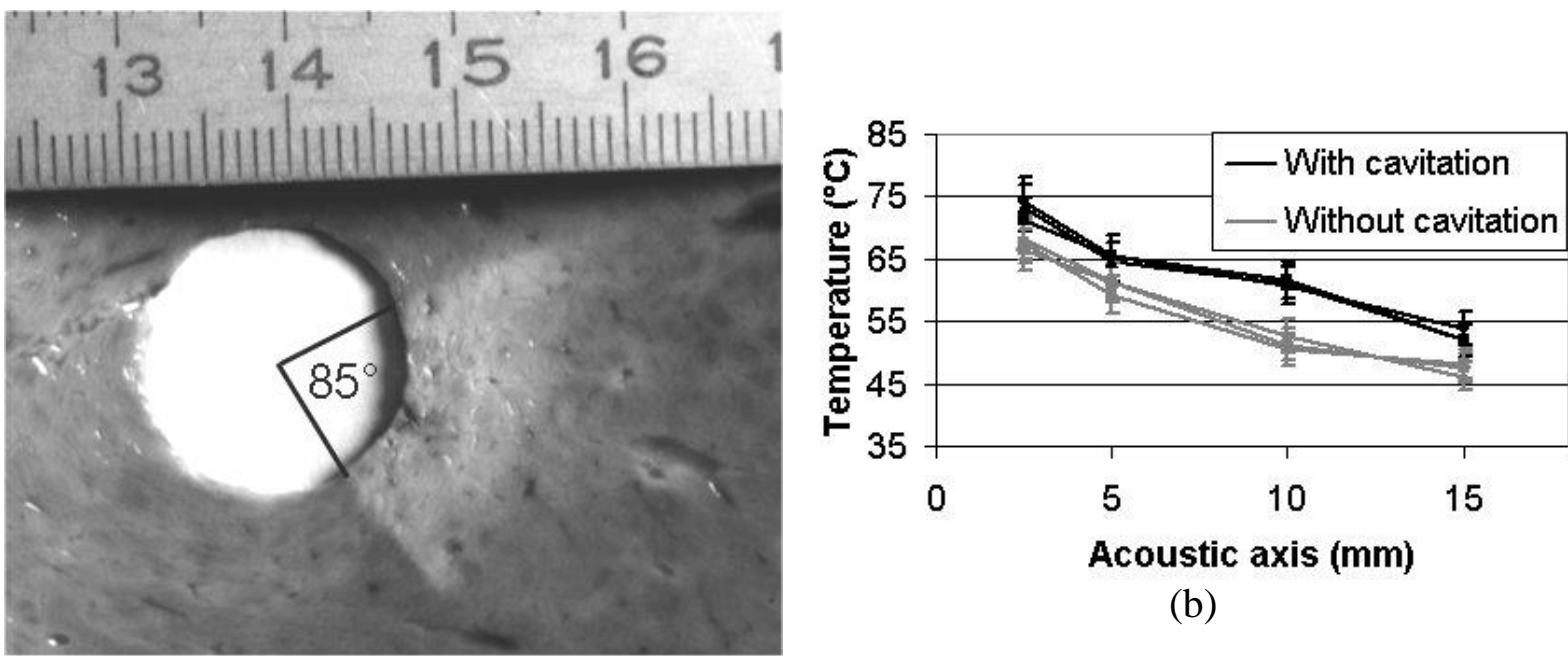

(a)

(b)

Figure 9 - D. Melodelima 

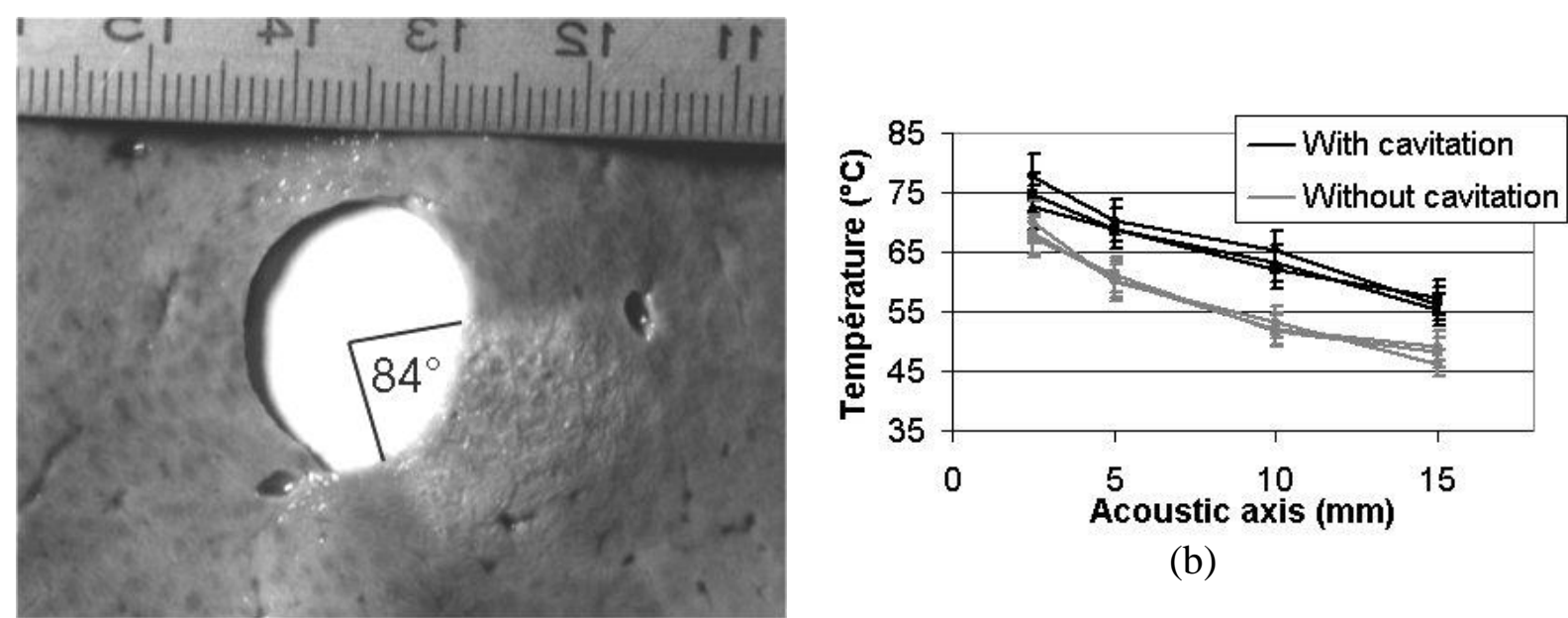

(a)

Figure 10 - D. Melodelima 

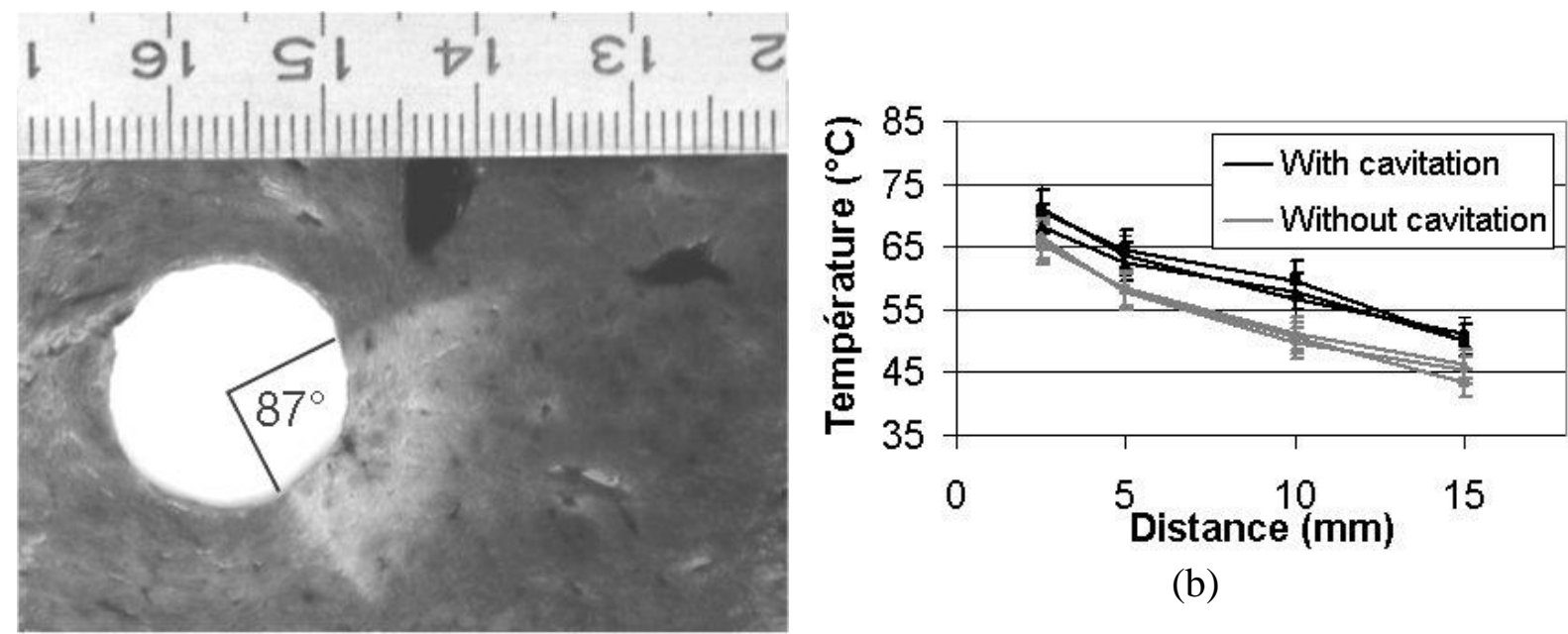

(a)

Figure 11 - D. Melodelima 


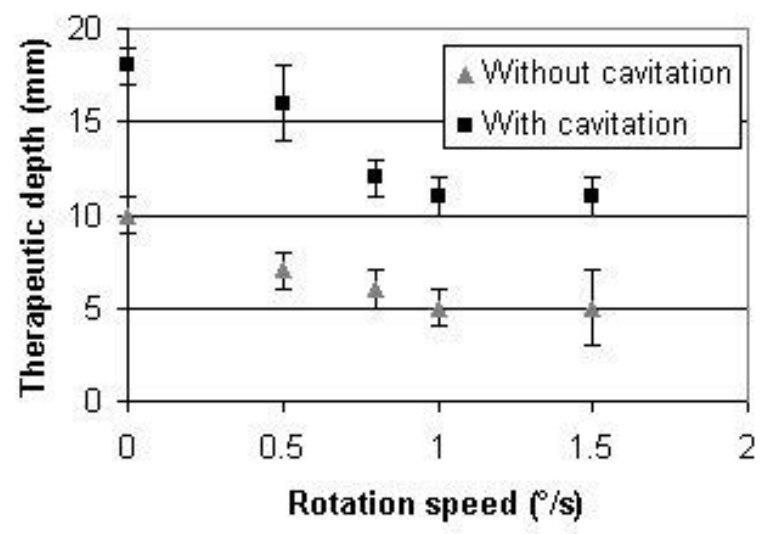

Figure 12 - D. Melodelima 
Table 1: Means and standard deviation of temperature measurements along the acoustic axis when only the cavitation was produced.

\begin{tabular}{lcccc}
\hline Measurement position: & $2.5 \mathrm{~mm}$ & $5 \mathrm{~mm}$ & $10 \mathrm{~mm}$ & $15 \mathrm{~mm}$ \\
\hline $\begin{array}{l}\text { Production of cavitation, } \\
\text { temperature mean values }\left({ }^{\circ} \mathrm{C}\right)\end{array}$ & 51.4 & 45.9 & 43.1 & 42.3 \\
\hline Standard deviation & 4.2 & 2.7 & 3.2 & 2.1 \\
\hline
\end{tabular}


Table 2: Means of necroses depth and angles treated with and without generating cavitation according to four speed of rotation $(0.5,0.8,1$ et $1.5 \%$ s).

\begin{tabular}{|c|c|c|c|c|}
\hline \multirow{2}{*}{$\begin{array}{c}\text { Speed of } \\
\text { rotation }(\%)\end{array}$} & \multicolumn{2}{|c|}{ Treatment depth $(\mathrm{mm})$} & \multicolumn{2}{c|}{ Angular section of the necrosis $\left(^{\circ}\right)$} \\
\cline { 2 - 5 } & without cavitation & with cavitation & without cavitation & with cavitation \\
\hline 0.5 & $7 \pm 1$ & $15 \pm 2$ & $82 \pm 3$ & $81 \pm 2$ \\
\hline 0.8 & $6 \pm 1$ & $12 \pm 1$ & $86 \pm 3$ & $86 \pm 2$ \\
\hline 1 & $5 \pm 1$ & $11 \pm 1$ & $85 \pm 2$ & $84 \pm 2$ \\
\hline 1.5 & $5 \pm 2$ & $11 \pm 1$ & $81 \pm 3$ & $87 \pm 2$ \\
\hline
\end{tabular}

